\title{
EL TURISMO GINEMATOGRÁFICO COMO RECURSO DIDÁCTICO: EL CASO DE JUEGO DE TRONOS EN OSUNA [SEVILLA]
}

\section{MOVIE INDUCED TOURISM AS A TEACHING RESOUREE: THE CASE OF THE GAME OF THRONES IN OSUNA [SEVILLA]}

\section{ÁLVARO PÉREZ GARCÍA}

Profesor Titular

Centro Universitario SAFA-Universidad de Jaén

Centro Universitario SAFA

Avda. Cristo Rey, 17, 23400, Úbeda (Jaén)

Tlfn: +34953796102

Email: alvaroperez@fundacionsafa.es

PALABRAS CLAVES

Recursos Educativos, Turismo

Cinematográfico, Osuna, Programación

Didáctica
KEY WORDS

Educational Resources, Movie induced tourism, Osuna, Didactic Programming 


\section{Resumen}

Cada vez son más las regiones que utilizan el cine como reclamo para atraer al turismo. El conocido como turismo cinematográfico (movie induced tourism) ha aumentado en los últimos años gracias a la repercusión de grandes producciones como "El señor de los anillos", "Star Wars" o "Juego de Tronos"; y la visión comercial que las ciudades y pueblos donde se han rodado han tenido, convirtiéndose asi en grandes atracciones para los numerosos fans de estos films y series. Teniendo esto en cuenta y recordando que el cine es, desde sus inicios, una importante herramienta didáctica y creativa que puede favorecer el aprendizaje de contenidos y la adquisición de competencias, esta comunicación pretende ofrecer algunas claves y ejemplos sobre la posible utilización didáctica del turismo cinematográfico y cómo pueden aprovechar las ciudades que están explotando este tipo de turismo para que sus centros educativos realicen proyectos en este sentido.

Por ello, se va a poner el ejemplo de Osuna, un pueblo de Sevilla que ha vivido un gran incremento turístico tras el rodaje de algunos capítulos de la serie de la HBO Juego de Tronos y cómo este impacto se puede aprovechar de forma educativa en los centros de la localidad. Para ello, se ofrecerá un ejemplo de Unidad Didáctica Integrada que englobe algunos de los criterios de evaluación, indicadores, objetivos, competencias y contenidos que el curriculum de la educación primaria expone en sus documentos normativos.

\section{Abstract}

There are more and more regions that use films to draw tourist attention. What is known as movie induced tourism has increased in recent years thanks to the influence of big productions as The Lord of the Rings, Star Wars or Game of Thrones; and so has the commercial vision of the cities and villages where they were shot, turning these places into a great attraction for the many fans of these films and series.

Taking this into account, and remembering that cinema is, from its beginnings, an important creative teaching tool, that can favour the learning of contents and the possible use and acquisition of the competences, this communication is intended to offer some clues and examples related to the possible didactic use of the tourist industry and how they can take advantage of the cities that are making use of this type of tourism so that its educational centers carry out projects in the same line.

Therefore, the example of Osuna will be used, a village of Seville that has undergone a great increase in tourism after they are filming of some Game of Thrones episodes and how this occurrence could be taken advantage in an educational way at local centers.

To do so, we will provide an example of an Integrated Teaching Unit including some assessment criteria, indicators, competences and contents that primary school curriculum presents in its standard documents. 


\section{Introducción}

El cine, desde su nacimiento a finales del siglo XIX, ha sido utilizado como herramienta didáctica para reforzar contenidos, trabajar la creatividad o introducir al alumnado en los medios audiovisuales, entre otros aspectos. Esto hace que el séptimo arte haya sido incluido como recurso en los planes curriculares de los distintos niveles educativos, ofreciendo múltiples posibilidades pedagógicas. Si a estas opciones educativas que ofrece el cine, añadimos el turismo, el proceso de enseñanza-aprendizaje se enriquece y aporta grandes alternativas para el profesorado y el alumnado.

En eso consiste este proyecto que se presenta a continuación, en utilizar una nueva vertiente turística, basada en el aprovechamiento de las grandes producciones cinematográficas que se han rodado en determinados lugares, y darle un enfoque didáctico-creativo para poder sacarle el máximo provecho posible en el ámbito escolar.

Para ello se va a hacer un repaso por el concepto de turismo cinematográfico, sus posibilidades, sus características, sus modalidades, etc., centrándonos en Osuna, ciudad que ha tenido una gran repercusión tras la grabación de varios capítulos de la serie Juego de Tronos.

También se hará un recorrido por las últimas experiencias que han utilizado el cine como recurso didáctico, que servirá para situar el estado de la cuestión de la educación cinematográfica.

Por último, se planteará una programación didáctica para aprovechar la repercusión del turismo cinematográfico en Osuna tras la repercusión mediática de la grabación de Juego de Tronos en la localidad.

\section{Objetivos}

El objetivo principal de este trabajo es mostrar las posibilidades educativas del turismo cinematográfico. Este objetivo principal se puede descomponer en otros objetivos de carácter más específico que se desgranan a continuación:

- Señalar el potencial didáctico-creativo del cine.

- Situar el concepto de turismo cinematográfico desde la visión de diferentes autores.

- Utilizar con fines didácticos el turismo cinematográfico a través de la realización de una programación didáctica.

\section{Metodología}

La metodología utilizada en este trabajo se basa en la búsqueda bibliográfica, para así poder situar el estado de la cuestión, tanto del turismo cinematográfico como del cine como recurso didáctico y, utilizando dicha información, construir una programación didáctica que nos sirva para trabajar el turismo cinematográfico en el aula. 


\section{El cine como recurso didáctico}

El cine desde sus inicios ha sido utilizado como una herramienta muy motivadora y educativa para ilustrar algunos de los contenidos curriculares de las distintas etapas educativas. El potencial que le ofrece su carácter audiovisual, unido a su cotidianeidad, lo convierten en un recurso muy positivo de cara a trabajar en el aula, aunque es necesaria una formación previa de docentes y alumnado para extraer el máximo beneficio. Como afirman Ortega Carrillo y Pérez García (2013):

"Desde el punto de vista didáctico el cine es una buena herramienta para la educación en valores, siempre que al espectador se le capacite para el análisis y la crítica de aquellas situaciones argumentales, símbolos o mensajes que orienten sobre los riesgos a evitar o que apoyen el desarrollo de la madurez personal y social y de afianzamiento de valores" (p. 300).

La relación del cine y la educación se puede analizar desde tres grandes perspectivas (Cobo Álvarez, 2002), "enseñanza del cine, enseñanza con el cine y enseñanza por el cine". Estas tres grandes vertientes abren miles de posibilidades para la introducción del séptimo arte en los currículos de los distintos niveles educativos.

Han sido muchas las experiencias e investigaciones que se han realizado en torno al uso educativo del cine (Martín y Guardia, 1976; De Pablos, 1986; Charles y Orozco, 1990; De la Torre, 1996; González Martel, 1996; Jiménez Pulido, 1999; González Subirá, 2002; Martínez-Salanova, 2002; Bergala, 2007; Gispert, 2009; García Amilburu y Landeros Cervantes, 2011), pero en este trabajo se van a reseñar algunas de las más recientes.

Peñalver Carrascosa (2015) señala las grandes posibilidades del cine como recurso didáctico en las aulas de secundaria, centrándose en el área de ciencias sociales, concretamente proponiendo una serie de actividades asociadas a la Historia antigua, aprovechando la capacidad del cine para recrear el pasado y la predisposición de un tipo de alumnado inmerso en las nuevas tecnologías y los audiovisuales como recurso didáctico.

El cine está considerado como un instrumento que fomenta la reflexión y el aprendizaje sobre múltiples temáticas. En este sentido, Vizoso Gómez (2016) puso en marcha una interesante experiencia en la que el objetivo principal era valorar el empleo del cine, concretamente la película Del revés, como un instrumento pedagógico que facilite la educación emocional y que promueva el desarrollo personal pleno.

También se convierte el cine en un interesante recurso para trabajar en el área de ciencias. Grilli Silva (2016) considera que las películas de ciencia ficción son un excelente recurso didáctico para la enseñanza de las ciencias, en general, y de las ciencias naturales, en particular gracias a la influencia que el cine tiene en la conformación de ideas sobre los científicos y el quehacer científico. Este autor presenta una forma de uso educativo de la película Jurassic Park, desarrollado en el marco de la formación inicial de profesores de Biología. En esta misma línea trabaja también Borrás Quirós (2016) que también valora la utilización del cine 
de ciencia ficción como recurso didáctico y su aplicación en Biología y Geología.

Incluso en los niveles universitarios el cine puede convertirse en una atractiva herramienta para trabajar diferentes asignaturas. Tal es el caso de la enseñanza del derecho administrativo como pretende Álvarez González (2015) en el grado de criminología utilizando la película española Celda 211, sobre la que se realizaron todas las actividades prácticas de la asignatura. Ortega Carrillo y Pérez García (2013) también implementaron en la Universidad de Granada un programa de formación didáctico-creativo para la utilización del cine digital en futuros maestros de distintas especialidades.

\section{Turismo cinematográfico}

La nueva corriente turística basada en visitar aquellos lugares o emplazamientos en los que se ha rodado una serie o una película de culto, se ha denominado "turismo cinematográfico" o "movie induced tourism". González Conde, Araújo Vila y Rodríguez Campo (2015) definen este término como el "turismo que sigue tras el éxito de una película o serie en el lugar en el que ésta fue rodada o está ambientada". Esta tipología surge a finales del siglo XX por el interés de las personas por conocer dónde se rodó su film favorito. Rodríguez Campo, Fraiz Brea y Alén González (2014) incluyen el turismo cinematográfico como una tipología emergente del turismo cultural.

Busby y Klug (2001, p.318), señalan una serie de tipos y características que definen al turismo cinematográfico:

a) Lugar de rodaje de una película como atracción en su propio derecho. Por un lado, hay lugares que no eran considerados destinos turísticos hasta su aparición en la pantalla mientras que otros ya eran percibidos como tal.

b) Turismo cinematográfico como parte de unas vacaciones principales. Algunos turistas visitarán el lugar que aparece en la televisión o en el cine o reservarán un tour sobre películas mientras se encuentran de vacaciones, sin un conocimiento previo de ese lugar.

c) Turismo cinematográfico que ocurre como el único y principal propósito fuera de intereses especiales. Consiste en la reserva de unas vacaciones a un destino específico como resultado directo de la aparición de éste en televisión.

e) Paquetes turísticos de turismo cinematográfico elaborados por el sector privado: Compañías de autobuses y tour operadores construyen paquetes como son Heartbeat Holidays o Peak Practice Breaks. 
Iconos sobre turismo cinematográfico considerados por los turistas un punto clave en sus visitas: Escenarios naturales, antecedentes históricos, actores, contenido simbólico y relaciones humanas, pueden servir como iconos para el turismo cinematográfico.

f) Turismo cinematográfico en lugares donde se cree que ha tenido lugar el rodaje. Los visitantes acuden a los lugares incluso si la película representa un escenario real diferente.

g) Turismo cinematográfico como parte de la mirada romántica. Los turistas románticos suelen centrarse en los lugares que han sido construidos y reforzados por la televisión y el cine en soledad y privacidad, estableciendo una relación semiespiritual con el lugar que se muestra.

h) Turismo cinematográfico por razones de peregrinaje, nostalgia y evasión. Este tipo de turismo aleja al visitante de la mundana realidad de la vida diaria. Los lugares de rodaje de películas como Field of Dreams (1989) y Steel Magnolias (1989) Ilegaron a ser puntos de peregrinaje en sí mismos. Programas de viaje. Un método mediante el cual los lugares y las personas han sido reinterpretados y comunicados a grandes audiencias.

Son muchos los autores que están estudiando este fenómeno en los últimos años, alabando las posibilidades desde distintos países. En este sentido, Pereira y Moraes (2013) realizaron una interesante investigación con estudiantes de cinematografía y la visión que ofrecía el cine nacional brasileño sobre el noroeste del país, y sus repercusiones en el turismo. Algo similar es lo que hicieron Figueira, Figueira y Monteiro (2015) con la región portuguesa de Alentejo.

La tesis doctoral de Sara Alexandra Soares Da Mata Nunes (2016) se centra en analizar la influencia del cine y la televisión en la notoriedad e imagen de algunas localidades y cómo favorecen en la elección de un destino turístico.

Millán, García y Díaz (2016) realizaron un estudio para evaluar los efectos de una ruta cinematográfica basada en la película Amanece, Que No Es Poco, para estudiar los beneficios tanto en número de visitantes como en el aspecto económico.

Otro ejemplo de repercusión económica de un film para una localidad es que muestran Torres-Romay, Ramahí García y García Mirón (2016) con el estudio del caso de la pequeña localidad cántabra de Comillas en la que se emplaza, mayoritariamente, el filme Primos (Daniel Sánchez Arévalo, 2011), uno de los largometrajes españoles con mejores resultados en taquilla en el año de su estreno. Aersten (2011), por su parte, señalaba que analizando un texto cinematográfico concreto, se pueden establecer diferentes estrategias narrativas a través de las cuales éste adquiere la función de texto promocional de un destino turístico concreto, en el caso de su investigación era la ciudad de Barcelona a través de la película de Woody Allen Vicky, Cristina, 
Barcelona (2008).

Con respecto a los festivales cinematográficos, también atraen gran cantidad de turismo a las localidades que los acogen. Así, Flores Ruiz (2015) analiza el caso del Festival Iberoamericano de Cine de Huelva, concluyendo que los beneficios económicos de organizar este evento supera a los costes.

Pero también han surgido otros términos relacionados con el turismo cinematográfico como el "city placement" (Méndiz, 2011):

"Emplazamiento de ciudades, regiones, monumentos, lugares turísticos y negocios de hospedaje y restauración en una producción audiovisual a cambio de una ayuda en la financiación, el rodaje o la promoción del filme, y con vistas a una promoción turística, a la mejora de su imagen en el exterior o a los beneficios económicos que cualquier rodaje comporta" (p.4).

Para finalizar este recorrido por los estudios realizados sobre el turismo cinematográfico se van a recoger dos experiencias que tienen como objetivo la localidad sevillana de Osuna y la repercusión del rodaje de la serie Juego de Tronos, que es el objeto principal de este trabajo. Por un lado, Seño Asencio (2015) señalaba el crecimiento que un pueblo como Osuna, que ya había sido emplazamiento de rodaje de otros films y series, si vio incrementada la llegada de turistas tras el rodaje de la superproducción de la HBO, algo que no había ocurrido con las otras producciones. Ramos Lobo y Pedregal Mateos (2015) analizaron a través de los Big Data la tendencia turística generada a partir del anuncio en 2014 de que Osuna sería uno de los destinos de rodaje de Juego de Tronos, demostrando finalmente que esa tendencia de búsqueda en google de los términos relacionados con la localidad y el rodaje de la serie se transformaron en un aumento también de visitas turísticas al pueblo sevillano.

\section{El turismo cinematográfico como recurso didáctico}

Una vez analizadas algunas de las experiencias más recientes de utilización del cine como recurso educativo y de haber situado la nueva tendencia turística "movie induced tourism", se van a unir ambas vertientes para crear una programación didáctica que aúne las ventajas que el cine posee como recurso turístico y como instrumento educativo. Todo ello centrado además en el pueblo de Osuna (Sevilla), aprovechando que se ha convertido en uno de los ejemplos más interesantes de influencia de una gran producción audiovisual en el aumento de visitas turísticas.

La programación de aula es el tercer y último paso en la concreción curricular y consiste en la planificación de la acción didáctica a lo largo del curso escolar referida a los aspectos curriculares "qué enseñar", "cómo enseñar" y "qué, cuándo y cómo evaluar" adaptados al grupo de alumnos/as y al nivel (curso) en el que se va a trabajar. Se refiere por tanto a una planificación anual que el maestro realiza al inicio de curso para establecer los aspectos fundamentales del proceso de enseñanza- aprendizaje sobre los que va a pivotar su acción didáctica con respecto al grupo de alumnos y alumnas y el curso en el que se encuentra.

En aquellos casos en que el profesor dirige su planificación y su actuación en el aula basándose 
en un libro de texto para cada área, es éste (el libro de texto y la editorial que lo haya elaborado) el que determina las directrices de la programación de aula. La postura contraria se presenta cuando es el propio docente el que elabora su programación de aula. En tal caso, independientemente de la opción que escoja para planificar [sea por unidades didácticas, proyectos, etc.], la programación se realizará en función de las necesidades y características de los alumnos de su grupo. La programación de aula reúne el conjunto de unidades didácticas integradas, proyectos de trabajo, proyectos de investigación, etc., que diseña un profesor o profesora determinada. La unidad didáctica integrada, proyecto de trabajo, o proyecto de investigación será, pues, el elemento específico de programación de aula para una determinada secuencia temporal y temática. Los diferentes elementos curriculares se planificarán atendiendo a la tarea central de la unidad de programación elegida para alcanzar los criterios de evaluación a través del desarrollo de los contenidos y el progreso de las competencias. Es fundamental en la programación el papel de los criterios de evaluación para valorar el grado de adquisición de las competencias clave y la consecución de los objetivos de área. $\mathrm{A}$ partir de ellos se fija los indicadores de evaluación (en el caso de la etapa de Educación Infantil el centro ha de concretar los criterios de evaluación de cada una de las áreas en las Propuestas Pedagógicas de ciclo).

A modo de ejemplo de programación, en la etapa de Educación Secundaria Obligatoria, concretamente en $4^{\circ}$ curso, se puede plantear una Unidad Didáctica Integrada titulada "Juego de Tronos", que se basaría en la creación de una empresa que sacara partido al turismo generado por el rodaje de la serie de la HBO en Osuna, en la que se integren de forma globalizada las áreas de "Iniciación a la Actividad Emprendedora y Empresarial”, “Educación Plástica, Visual y Audiovisual” y “Economía”.

En este sentido, los criterios de evaluación que se van a trabajar en esta programación y que se extraen del curriculum oficial de la Educación Secundaria (Real Decreto 1105/2014, de 26 de diciembre, por el que se establece el currículo básico de la Educación Secundaria Obligatoria y del Bachillerato) podrían ser: Crear un proyecto de empresa en el aula describiendo las características internas y su relación con el entorno así como su función social, identificando los elementos que constituyen su red logística como proveedores, clientes, sistemas de producción y comercialización y redes de almacenaje entre otros; realizar actividades de producción y comercialización propias del proyecto de empresa creado aplicando técnicas de comunicación y trabajo en equipo; describir los diferentes tipos de empresas y formas jurídicas de las empresas relacionando con cada una de ellas sus exigencias de capital y las responsabilidades legales de sus propietarios y gestores así como las interrelaciones de las empresas su entorno inmediato, enfocado a la empresa turística; analizar las características principales del proceso productivo; realizar composiciones creativas a partir de códigos utilizados en cada lenguaje audiovisual, mostrando interés por los avances tecnológicos vinculados a estos lenguajes; identificar los distintos elementos que forman la estructura narrativa y expresiva básica del lenguaje audiovisual y multimedia, describiendo correctamente los pasos necesarios para la producción de un mensaje audiovisual y valorando la labor de equipo.

Con respecto a los contenidos a trabajar en esta UDI, se plantearían: la idea de proyecto de empresa; el entorno, el rol social de la empresa; elementos y estructura de la empresa; el plan de empresa; la función 
comercial y de marketing; ayudas y apoyo a la creación de empresas; tipos de empresa; criterios de clasificación, forma jurídica, funciones y objetivos; proceso productivo y factores productivos; fuentes de financiación de las empresas; ingresos, costes y beneficios; obligaciones fiscales de las empresas; creación audiovisual.

Por último, los estándares de aprendizaje evaluables: determina la oportunidad de un proyecto de empresa identificando las características y tomando parte en la actividad que esta desarrolla; describe la relación del proyecto de empresa con su sector, su estructura organizativa y las funciones de cada departamento identificando los procedimientos de trabajo en el desarrollo del proceso productivo o comercial; crea materiales de difusión y publicidad de los productos y/o servicios del proyecto de empresa incluyendo un plan de comunicación en internet y en redes sociales aplicando los principios del marketing; explica las posibilidades de financiación del día a día de las empresas diferenciando la financiación externa e interna, a corto y a largo plazo, así como el coste de cada una y las implicaciones en la marcha de la empresa; distingue las diferentes formas jurídicas de las empresas y las relaciona con las exigencias requeridas de capital para su constitución y responsabilidades legales para cada tipo; valora las formas jurídicas de empresas más apropiadas en cada caso en función de las características concretas aplicando el razonamiento sobre clasificación de las empresas; identifica los diferentes tipos de empresas y empresarios que actúan en su entorno así como la forma de interrelacionar con su ámbito más cercano y los efectos sociales y medioambientales, positivos y negativos, que se observan; elabora imágenes digitales utilizando distintos programas de dibujo por ordenador; proyecta un diseño publicitario utilizando los distintos elementos del lenguaje gráfico-plástico; realiza, siguiendo el esquema del proceso de creación, un proyecto personal.

Las principales competencias clave (Orden ECD/65/2015) que se podrían adquirir en este proyecto de trabajo son: "Comunicación lingüística", "Competencias sociales y cívicas", "Competencia Digital" y "Sentido de iniciativa y espíritu emprendedor".

Con respecto a las tareas para trabajar estos aspectos curriculares se podría plantear la realización de un proyecto final que consistiría en la elaboración de un vídeo promocional para aumentar el turismo en Osuna a partir de la serie Juego de Tronos y así darle difusión a la empresa que el alumnado haya creado. Con respecto a las actividades, todas irían dirigidas a la consecución de ese gran producto final, a saber: idear una empresa de promoción turística; estudio de las potencialidades turísticas del pueblo de Osuna; estudios de mercado; guionización, grabación y edición de productos audiovisuales artesanales; visionado crítico de anuncios publicitarios.

Por último, la Unidad Didáctica Integrada finalizaría con la evaluación, que se realizaría a través de una rúbrica, "instrumento que facilita la evaluación del desempeño de los estudiantes mediante una matriz de criterios específicos que permiten asignar a éste un valor, basándose en una escala de niveles de desempeño y en un listado de aspectos que evidencian el aprendizaje del estudiante sobre un tema particular" (López García, 2014). 
Con respecto a Educación Primaria y Educación Infantil, sería más recomendable trabajar a través de Proyectos de Trabajo, aunque se podría realizar una programación similar teniendo en cuenta los contenidos, criterios de evaluación y estándares de aprendizaje evaluables de cada etapa, ciclo y área.

\section{Conclusiones}

Las grandes posibilidades didácticas del cine, unidas al enorme avance del turismo cinematográfico, hacen que la combinación de ambas disciplinas se convierta en una potente herramienta educativa para trabajar diversas áreas del currículum oficial.

En este sentido, son muchos los autores que han realizado experiencias de integración del cine en el aula, prácticamente desde el nacimiento del séptimo arte, lo que sirve como base a la hora de realizar proyectos futuros en este ámbito. Además, cada vez son más las investigaciones que refuerzan la tendencia del turismo inducido por el cine, ayudando también a tenerlo en cuenta de cara a su uso escolar.

Teniendo ello en cuenta, se pueden realizar programaciones didácticas bajo distintas formas (Unidades Didácticas Integradas, Proyectos de Trabajo, Tareas Integradas, etc.) que bajo un prisma constructivista motivarán al alumnado y fomentarán la creación audiovisual, el emprendimiento y el aprendizaje.

Así pues, la realización de programaciones didácticas sobre cine y turismo en centros educativos de localidades que hayan sido escenarios naturales de producciones cinematográficas y televisivas va a ayudar al alumnado a conocer mejor la historia y cultura de sus poblaciones, a valorar y respetar más el patrimonio, a dar publicidad a sus municipios y a disfrutar del cine desde su contemplación y desde la propia creación de proyectos artesanales audiovisuales.

\section{Referencias}

- Aersten, V.U. (2011). El cine como inductor del turismo. La experiencia turística en Vicky, Cristina, Barcelona. Razón y palabra, 77.

- Álvarez González, A.M. (2015). El cine como recurso docente aplicable a la enseñanza del Derecho Administrativo. REJIE: Revista Jurídica de Investigación e Innovación Educativa, 11, 97-108.

- Bergala, A. (2007). La Hipótesis del Cine: pequeño tratado sobre la transmisión del cine en la escuela y fuera de ella. Barcelona: Laertes, S.A. de Ediciones.

- Borrás Quirós, B. (2016). El cine de ciencia ficción como recurso didáctico y su aplicación en Biología y Geología durante la Educación Secundaria Obligatoria. Didácticas Específicas, 14, 144-150.

- Busby, G. y Klug, J. (2001). Movie induced tourism: The challenge of measurement and other issues. Journal of Vacation Marketing, 7 (4), 316-332.

- Charles Creel, M. y Orozco Gómez, G. (1990). Educación para la recepción: hacia una lectura crítica 
de los medios. México: Editorial Trillas.

- $\quad$ Cobo Álvarez, M. (2002). Aprendiendo con el cine. Sevilla: Publicaciones MCEP.

- De Pablos, J. (1986). Cine y Enseñanza. CIDE, Madrid: Ministerio de Educación y Ciencia.

- $\quad$ Figueira, A.; Figueira, F. y Monteiro, S. (2015). Turismo e cinema: a importância de uma film commission na promoção do destino Alentejo. International Journal of Scientific Management and Tourism, 3, $29-37$.

- $\quad$ Flores Ruiz, D. (2015). Turismo cinematográfico y desarrollo económico local. El festival de cine de Huelva. Cuadernos de Turismo, 36, 175-196.

- García Amilburu, M. y Landeros Cervantes, B. (2011). Teoría y práctica del análisis pedagógico del cine. Madrid: UNED.

- $\quad$ Gispert, E. (2009). Cine, ficción y educación. Barcelona: Lartes Ediciones.

- $\quad$ González Conde, A.; Araújo Vila, N. y Rodríguez Campo, L. (2015). Turismo cinematográfico: La conquista on line de nuevos mercados. ROTUR, Revista de Ocio y Turismo, 9, 17-34.

- $\quad$ González Martel, J. (1996). El cine en el universo de la ética. El cinefórum. Madrid: Grupo ANAYA.

- $\quad$ González Subirá, J.F. (2002). Aprender a ver cine. Madrid: RIALP.

- Grilli Silva, J. (2016). Cine de ciencia ficción y enseñanza de las ciencias. Dos escuelas paralelas que deben encontrarse en las aulas. Revista Eureka sobre Enseñanza y Divulgación de las Ciencias, 13 (1), 137- 148.

- Jiménez Pulido, J. (1999). El Cine como modelo educativo. Madrid: Ediciones Hermes.

- $\quad$ López García, J.C. (2014-12-01). Cómo construir Rúbricas o Matrices de Valoración. [Mensaje en un blog]. Recuperado de http://eduteka.icesi.edu.co/articulos/MatrizValoracion

- Martín Martín, A. y Guardia González, S. (1976). Comunicación audiovisual y educación. Salamanca: Anaya.

- Martínez-Salanova Sánchez, E. (2002). Aprender con el cine, aprender de película. Una visión didáctica para aprender e investigar con el cine. Huelva: Grupo Comunicar.

- Mendiz Nogueró, A. (2011). Emplazamiento de ciudades en el cine ("City placement”): una estrategia de doble sentido entre la producción cinematográfica y la industria del turismo. En Actas del III Congreso Internacional Latina de Comunicación Social. Universidad de La Laguna.

- $\quad$ Millán, A.; García, J.A. y Díaz, E. (2016). Film-induced tourism: A latent class segmentation based on satisfaction and future intentions. PASOS, Revista de Turismo y Patrimonio Cultural, 14 (4), 875-888.

- $\quad$ Ortega Carrillo, J. A. y Pérez García, A. (2013). El cine digital en la formación inicial del profesorado: una experiencia innovadora realizada en la Universidad de Granada. Educación XX1, 16 (2), 297-320. doi: 10.5944/educxx1.16.2.2644

- Peñalver Carrascosa, T. (2015). El cine como recurso didáctico: una propuesta de programación 
didáctica. Edetania, 47, 221-232.

- $\quad$ Pereira Neto, F.S. y Moraes Schmidlin, I.O. (2013). Turismo induzido por filmes: a imagem do nordeste propagada pelo cinema brasileiro no ponto de vista do estudante de cinema no ceará. PODIUM: Sport, Leisure and Tourism Review, 2 (2), 1-31.

- Ramos Lobo, J. y Pedregal Mateos, B. (2015). Big Data y turismo cinematográfico: ¿Un factor de predicción? El caso de Juego de Tronos en Osuna. En J.L. Jiménez-Caballero y otros (coords.), Impulso al desarrollo económico a través del turismo: VIII Jornadas de Investigación en Turismo. Sevilla, 233-256.

- Real Decreto 1105/2014, de 26 de diciembre, por el que se establece el currículo básico de la Educación Secundaria Obligatoria y del Bachillerato.

- $\quad$ Rodríguez Campo, L.; Fraiz Brea, J.A. y Alén González, E. (2014). El turismo cinematográfico como tipología emergente del turismo cultural. Pasos, Revista de Turismo y Patrimonio Cultural, 12 (1), 159-171.

- Seño Asensio, F. (2015). Una aproximación al turismo inducido por el cine. El caso de Osuna y Juego de Tronos. Cuadernos de los Amigos de los Museos de Osuna, 17, 164-168.

- Soares Da Mata Nunes, S.A. (2016). Los destinos turísticos en las producciones de cine y televisión. Influencia en su notoriedad e imagen de marca y en la elección del consumidor. Tesis Doctoral inédita. Universidad de Extremadura.

- Torre, S. de la (coord.) (1996). Cine formativo. Una estrategia innovadora para los docentes. Barcelona: Octaedro.

- Torres-Romay, E.; Ramahí García, D. y García Mirón, S. (2016). Una aproximación a las nociones del turismo cinematográficamente inducido y emplazamiento de lugar. El caso de Primos (Daniel Sánchez Arévalo, 2011). En C. Mateos y J. Herrero (Coords.), La pantalla insomne. $2^{a}$ Edición ampliada. Universidad de la Laguna: CAC, 1339-1363.

- Vizoso Gómez, C.M. (2016). "Del revés" como recurso didáctico para la educación emocional. Revista DIM: Didáctica, Innovación y Multimedia, 34. 